\title{
Bone marrow involvement by subcutaneous Panniculitis-like T-cell lymphoma: a report of three cases
}

Juehua Gao ${ }^{1}$, Steve J Gauerke ${ }^{2}$, Maria E Martinez-Escala ${ }^{3}$, Joan Guitart ${ }^{3}$, Beverly P Nelson ${ }^{1}$, Amy Chadburn ${ }^{1}$ and LoAnn C Peterson ${ }^{1}$

${ }^{1}$ Department of Pathology, Northwestern University Feinberg School of Medicine, Chicago, IL, USA;

${ }^{2}$ Department of Pathology, Portsmouth Naval Medical Center, Portsmouth, VA, USA and ${ }^{3}$ Department of

Dermatology, Northwestern University Feinberg School of Medicine, Chicago, IL, USA

\begin{abstract}
Subcutaneous panniculitis-like T-cell lymphoma is a rare subtype of cutaneous T-cell lymphoma. Virtually all cases are confined to the subcutaneous adipose tissue. In this report, we describe the first small series of subcutaneous panniculitis-like T-cell lymphoma (three patients) with bone marrow involvement. All patients presented with skin or soft tissue nodules, fever, and constitutional symptoms, and were diagnosed with subcutaneous panniculitis-like T-cell lymphoma based on the characteristic morphologic and immunophenotypic features of the subcutaneous lesions. Bone marrow core biopsies in these cases showed focal involvement by lymphoma with pathologic features similar to those seen in the diagnostic biopsies. Our observations suggest bone marrow involvement by subcutaneous panniculitis-like T-cell lymphoma does occur, and can be identified histologically and confirmed using standard immunohistochemistry. Our findings raise awareness of bone marrow involvement in this rare entity. However, the incidence and significance of bone marrow involvement in subcutaneous panniculitis-like T-cell lymphoma requires further evaluation. Modern Pathology (2014) 27, 800-807; doi:10.1038/modpathol.2013.191; published online 8 November 2013
\end{abstract}

Keywords: bone marrow involvement; immunophenotype; subcutaneous panniculitis-like T-cell lymphoma

Subcutaneous panniculitis-like T-cell lymphoma is a rare subtype of cutaneous lymphoma. It previously consists of neoplastic cells of either $\alpha \beta$ or $\gamma \delta$ type. The 2008 World Health Organization (WHO) classification no longer considers cases composed of $\mathrm{T}$ cells expressing the $\gamma \delta$ as a subtype of subcutaneous panniculitis-like T-cell lymphoma; these cases are now classified as primary cutaneous $\gamma \delta$ T-cell lymphoma. ${ }^{1}$ Subcutaneous panniculitis-like T-cell lymphoma most often presents as recurrent painless subcutaneous nodules or indurated plaques. Histopathologic examination demonstrates a dense infiltrate of markedly atypical lymphoid cells localized to the panniculus, and often rimming individual adipocytes. The neoplastic cells exhibit a phenotype of cytotoxic T cells that are CD3 + , CD4 - , $\mathrm{CD} 8+$, with expression of the cytotoxic proteins granzyme B, TIA-1, and perforin. Expression of

Correspondence: Dr J Gao, MD, Department of Pathology, Northwestern University Feinberg School of Medicine, Feinberg Pavilion, Room 7-209A, 251 E Huron St., Chicago, IL 60611, USA. E-mail: j-gao@northwestern.edu

Received 31 May 2013; accepted 3 September 2013; published online 8 November 2013
BetaF1 confirms that the T cells are $\alpha \beta$ subtype and helps to differentiate the lesions from primary cutaneous $\gamma / \delta$ T-cell lymphoma. In previously reported cases of subcutaneous panniculitis-like T-cell lymphoma, the disease was localized to the subcutaneous adipose tissue without involvement of other organs. Here, we report three cases with bone marrow involvement, and describe the morphologic and immunohistochemical findings.

\section{Materials and methods}

Cases

The bone marrow aspirates, core biopsies, and immunohistochemical stains were retrieved from the files of the Department of Pathology Northwestern University Feinberg School of Medicine. The corresponding skin biopsies were retrieved from the archives of the Department of Dermatopathology of Northwestern Medical Faculty Foundation. The diagnosis of subcutaneous panniculitis-like T-cell lymphoma was confirmed based on review of skin biopsies using the criteria outlined in the 2008 WHO Classification of Tumours of Haematopoietic and 
Lymphoid Tissue. ${ }^{1}$ Electronic medical records were reviewed for additional clinical information. This study was approved by the Institutional Review Board of Northwestern University.

\section{Immunohistochemistry}

Immunohistochemical staining was performed on bone marrow core biopsy sections at the time of the diagnosis in two patients (cases 1 and 2) and retrospectively in one patient (case 3) following protocols developed in the Northwestern Memorial Hospital Immunohistochemical Laboratory. Immunostaining for CD3 and CD8 was performed on the BenchMark XT (Ventana Medical Systems, Tucson, AZ, USA). Immunostaining for CD4, BetaF1, and CD56 was performed on Dako autostainer (Dako, Carpinteria, CA, USA). The primary antibodies used were as follows: monoclonal CD3 (Leica Microsystems, Buffalo Grove, IL, USA), CD4 (Leica, 1:20), CD8 (Dako, 1:20), CD56 (Vector Lab, Burlingame, CA, USA, 1:300), BetaF1 (Thermo Fisher Scientific, Middletown, VA, USA, 1:40) and $\gamma \delta$ (Thermo Fisher Scientific, 1:30).

\section{Flow Cytometric Analysis}

Fresh cell suspensions were prepared from the tissue (cases 1 and 2) or bone marrow aspirates (cases 1, 2, and 3) as described previously. ${ }^{2}$ Samples were analyzed on the BD Biosciences LSR II 6-color flow cytometer, and data analysis was performed using FACSDiva software (BD Biosciences, San Jose, CA, USA). The following monoclonal antibodies were used: CD4- PerCP-Cy5.5, CD8 APC-H7, Granzyme B-FITC, $\alpha \beta$-FITC, and $\gamma \delta$-PE from BD Biosciences, and CD3-APC, CD56 PE-Cy7, TIA1-PE, CD16-PE, and CD57-FITC from Beckman Coulter.

\section{Molecular Analysis}

Molecular analyses to assess for the presence of T-cell receptor gamma chain gene rearrangements were performed on the B5 fixed decalcified bone marrow core biopsy sections (cases 1 and 2) and formalinfixed paraffin-embedded skin biopsy section (case 1) using a multiplex PCR-based clonality assay (Invivoscribe, San Diego, CA, USA). The PCR products are detected by capillary gel electrophoresis on an ABI 3130XL genetic analyzer (Applied Biosystems, Foster City, CA, USA). A population was considered clonal if the height of the peak was $>3$ times the height of the third highest peak in a given range of DNA sizes.

\section{Results}

\section{Clinical Presentation}

Patient 1 was a 32-year-old female with no significant past medical history. She initially presented with multiple subcutaneous bumps, first diagnosed as lipomas, on her abdomen and chest associated with high fevers, night sweats, and chills. Physical exam and a standard CT did not demonstrate lymphadenopathy, whereas a PET-CT showed numerous areas of abnormal metabolic activity, predominantly in the cutaneous and subcutaneous soft tissues of abdomen. Blood tests showed an elevated LDH 634 U/l (reference range: <200 U/l), normochromic, normocytic anemia with hemoglobin of $9 \mathrm{~g} / \mathrm{dl}$ (reference range: 11.6-15.4 g/dl), hypoalbuminemia $2.9 \mathrm{~g} / \mathrm{dl}$ (reference range: $3.5-5.0 \mathrm{~g} / \mathrm{dl}$ ), abnormal liver enzymes AST $245 \mathrm{U} / \mathrm{l}$ (reference range: <40 U/l), ALT $258 \mathrm{U} / \mathrm{l}$ (reference range: <48 U/l), and elevated alkaline phosphatase 302 U/l (reference range: 30-115 U/l). The bumps rapidly enlarged, were biopsied and diagnosed as subcutaneous panniculitis-like T-cell lymphoma. She was initially determined as T2N0M0 based on TNM classification system, ${ }^{3}$ but a bone marrow biopsy showed focal involvement by lymphoma, which upgraded her disease to T2N0M1. She was treated with six cycles of chemotherapy using a regimen for aggressive lymphoma (cyclophosphamide, vincristine, doxorubicin, dexamethasone, methotrexate, and cytarabine), obtaining complete remission, with rapid resolution of her fever and constitutional symptoms. She is in complete remission 2 years after treatment.

Patient 2 was a 21-year-old man who presented with a deep indurated nodule of the left anterior chest wall and B-symptoms including fever, night sweats, and weight loss. His initial laboratory tests showed a highly elevated D-dimer $14755 \mathrm{ng} / \mathrm{ml}$ (reference range $<243 \mathrm{ng} / \mathrm{ml}$ ), low fibrinogen $73 \mathrm{ng} / \mathrm{dl}$ (reference range: $221-498 \mathrm{ng} / \mathrm{dl}$ ), high LDH $763 \mathrm{U} / \mathrm{l}$ (reference range: <200 U/L), and abnormal AST $102 \mathrm{U} / \mathrm{L}$ (reference range: <40 U/L) and ALT 69 (reference range: <48 U/1). A standard CT scan showed no evidence of lymphadenopathy or splenomegaly. Biopsy of the chest wall lesion showed subcutaneous panniculitis-like T-cell lymphoma. A subsequent bone marrow biopsy demonstrated focal involvement by lymphoma. Although there was a clinical concern, a diagnosis of hemophagocytic syndrome was not confirmed. He was staged as T1aN0M1 and was started on chemotherapy (cyclophosphamide, methotrexate, etoposide, and dexamethasone). His chest wall lesion developed cavitation after chemotherapy that was thought to be related to tumor necrosis. After completion of chemotherapy, restaging studies including PET-CT and bone marrow biopsy confirmed complete remission. The patient did well for 2 years until he developed a nodule to his left shoulder. A biopsy showed recurrent subcutaneous panniculitis-like T-cell lymphoma. A PET-CT scan and bone marrow biopsy showed no other sites of disease, and he was treated with gemcitabine and oxaliplatin, consolidative radiation (750 cGy) followed by an allogeneic matched sibling donor stem cell transplant. Patient is now $>1$ year post transplant, with mild to moderate oral and gastrointestinal graft versus host disease which responds to steroids. 
Table 1 Clinical features of the three cases of subcutaneous panniculitis-like T-cell lymphoma

\begin{tabular}{|c|c|c|c|}
\hline & Case 1 & Case 2 & Case 3 \\
\hline $\operatorname{Age}(Y) / \operatorname{sex}$ & $32 / \mathrm{F}$ & $21 / \mathrm{M}$ & $50 / \mathrm{F}$ \\
\hline $\begin{array}{l}\text { Location of the skin } \\
\text { lesion }\end{array}$ & Chest & Anterior chest & Bilateral thigh \\
\hline \multicolumn{4}{|l|}{$C B C$} \\
\hline Hemoglobin (g/dl) & 9.0 & 10.9 & 11 \\
\hline WBC $\left(\times 10^{9} / \mathrm{l}\right)$ & 6.6 & 4.2 & 4.1 \\
\hline Platelets $\left(\times 10^{9} / \mathrm{l}\right)$ & 268 & 136 & 202 \\
\hline LDH & High & High & Not known \\
\hline Constitutional symptoms & Yes & Yes & Yes \\
\hline Lymphadenopathy & No & No & No \\
\hline Splenomegaly & No & No & No \\
\hline $\begin{array}{l}\text { Hemophagocytic } \\
\text { syndrome }\end{array}$ & No & Suspicious but not confirmed & $\begin{array}{l}\text { Suspicious but not } \\
\text { confirmed }\end{array}$ \\
\hline Treatment & Chemotherapy & $\begin{array}{c}\text { Chemotherapy, radiation, and stem cell } \\
\text { transplant }\end{array}$ & Cyclosporine A \\
\hline \multirow[t]{2}{*}{ Follow-up } & \multirow[t]{2}{*}{$\begin{array}{c}\text { Complete remission after } 2 \\
\text { years }\end{array}$} & Recurrence after 2 years & \multirow[t]{2}{*}{$\begin{array}{l}\text { Died } 9 \text { months after } \\
\text { diagnosis }\end{array}$} \\
\hline & & Remission after stem cell transplant & \\
\hline
\end{tabular}

Patient 3 was a 50-year-old female presented with bilateral reddish skin lesions involving the thighs. Skin biopsy was diagnosed as subcutaneous panniculitis-like T-cell lymphoma. Bone marrow biopsy at the time showed focal involvement by lymphoma. No other laboratory data were available in the medical record. She was treated with cyclosporine A for 9 months but with unsuccessful attempts to taper medication. She later developed mild neutropenia, and a repeat bone marrow biopsy again showed focal involvement by subcutaneous panniculitis-like T-cell lymphoma. The patient died 9 months after initial diagnosis from clinically suspected hemophagocytic syndrome; however, she did not meet the criteria needed for the diagnosis of hemophagocytic syndrome. ${ }^{4}$ Furthermore, morphologic evidence of hemophagocytosis was not present in the bone marrow. (Table 1).

\section{Skin and Soft Tissue Biopsies}

Biopsies of the skin or soft tissue masses from the three patients demonstrated similar morphologic features. There was an abnormal subcutaneous lymphoid infiltrate with prominent rimming of individual adipocytes by atypical lymphoid cells. The lymphoid cells were small to intermediate in size with scant cytoplasm and occasional inconspicuous nucleoli (Figure 1a). Some of the neoplastic cells had hyperchromatic nuclei. Focal areas of karyorrhexis admixed with histiocytes containing phagocytic debris were identified. In addition, in case 2, focal necrosis was seen. Immunohistochemical stains performed on the paraffin tissue sections of the skin lesions shows that the lymphocytes in the infiltrates rimming the adipocytes were CD3 +, CD8 + cytotoxic T cells (all cases) (Figure 1b), and
CD4 and CD56 negative (performed on cases 1 and 2). Immunohistochemical staining for BetaF1 was positive (cases 1 and 2), indicating the lymphocytes were of the $\alpha \beta$ phenotype. The morphologic and immunophenotypic findings were consistent with the diagnosis of subcutaneous panniculitis-like T-cell lymphoma. In addition, flow cytometric immunophenotypic studies of the soft tissue biopsies were available in cases 1 and 2. Only a small number of antigenically unremarkable $\mathrm{T}$ cells were seen by flow cytometry from the soft tissue biopsy of case 1 . Biopsy of soft tissue mass in case 2 yielded more numerous lymphocytes, virtually all of which were $\mathrm{CD} 3+, \mathrm{CD} 4-, \mathrm{CD} 8+, \alpha \beta+, \operatorname{dim} \mathrm{CD} 56+$, CD16 - , CD57-, TIA1 + , and granzyme B -, consistent with abnormal cytotoxic $\mathrm{T}$ cells (Figure 1c). Molecular analysis of the T-cell receptor gamma chain by PCR was performed in case 1, and showed the presence of a clonal T-cell population.

\section{Peripheral Blood and Bone Marrow}

The peripheral blood smears in all cases were morphologically unremarkable, but there was a normochromic normocytic anemia. Review of the bone marrow aspirate smears from each case demonstrated multilineage hematopoiesis with appropriate maturation and no increase in lymphocytes. The cellularity of the core biopsies varied from mildly hypocellular (case 2), normocellular (case 3) to moderately hypercellular (case 1). None of the cases showed large lymphoid infiltrates. However, scattered foci of lymphocytes encircling fat cells were seen in all cases (Figure 2). The lymphocytes were small to medium in size, often with hyperchromatic and/or elongated nuclei. The rimming of the adipocytes was multifocal, but the 

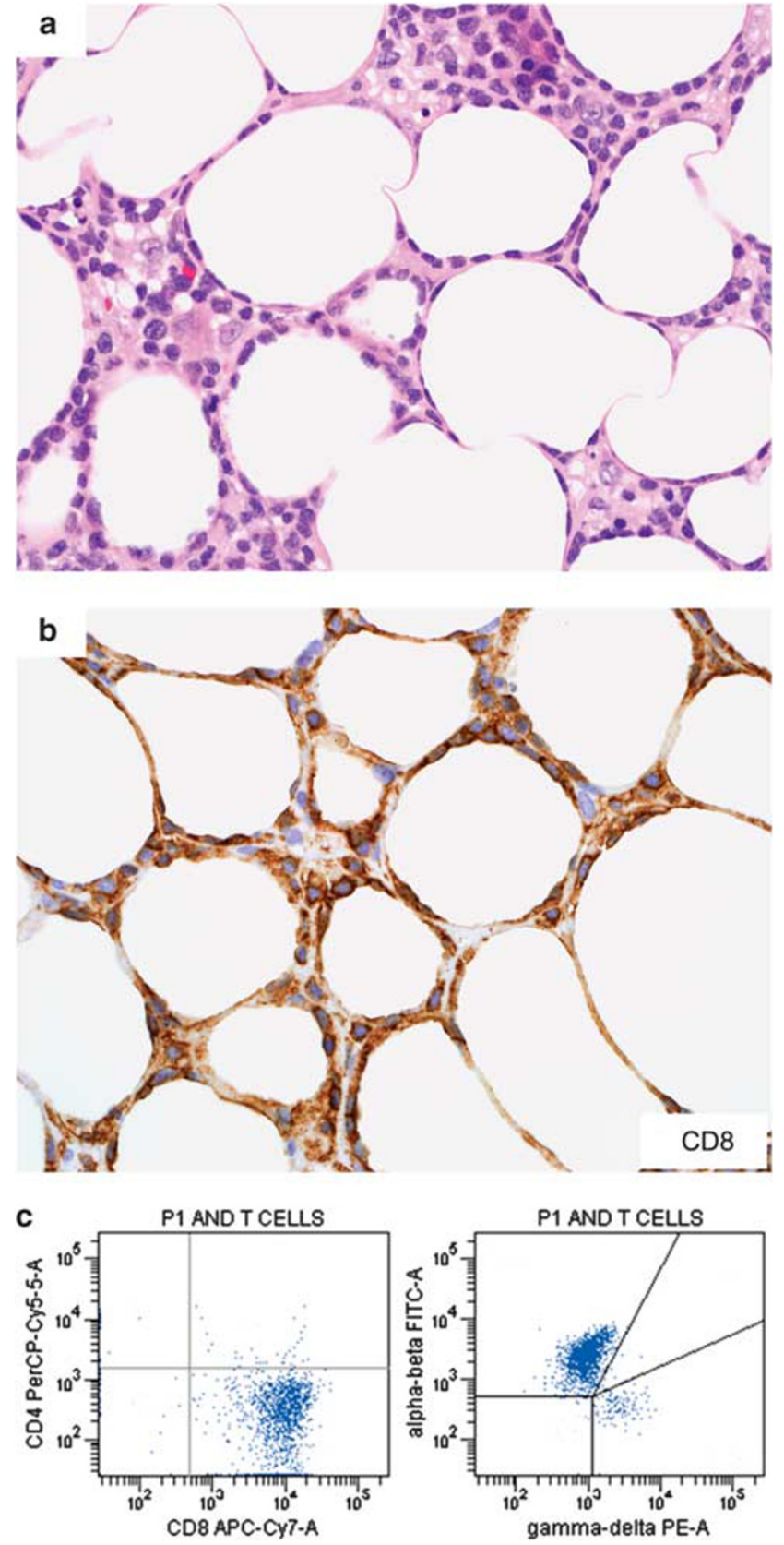

Figure 1 Case 2: (a) Atypical lymphoid infiltrate in the subcutaneous tissue with prominent rimming of the lymphocytes around the adipocytes (hematoxylin and eosin stain, original magnification $\times 600$ ). (b) The lymphocytes were CD8 + based on immunostaining (immunoperoxidase, original magnification $\times 600$ ). (c) Flow cyometric analysis performed on the subcutaneous tissue biopsy confirmed the $\mathrm{T}$ cells were CD8 $+\alpha \beta$ phenotype.

morphologic changes were subtle and often involved just a few fat cells. Cases 1 and 3 also showed increased numbers of histiocytes within the marrow (Figure 3), including some containing cytoplasmic debris. The infiltrates and the circling of adipocytes by phagocytic cells resulted in illdefined adipocyte cytoplasmic borders in the affected areas.
Immunostains confirmed that the fat cells were rimmed by CD $3+$ and CD $8+$ T cells. Immunostaining for BetaF1 and $\gamma \delta$, performed in cases 1 and 3 , confirmed the $\alpha \beta$ phenotype of the infiltrating lymphocytes. Flow cytometric analysis of bone marrow aspirates performed on cases 1 and 3 were unremarkable and showed a normal percentage of $\mathrm{T}$ cells with a normal (case 1) or elevated (case 3) CD4: CD8 ratio. T-cell receptor gene rearrangement studies were negative for clonal populations in the two cases tested (cases 1 and 2). Patient 2 had two follow-up bone marrow biopsies performed 4 months after treatment, the latter at the time of cutaneous disease recurrence. Neither biopsy showed morphologic evidence of involvement by lymphoma. Molecular studies in both cases were negative for a clonal T-cell receptor gene rearrangement (Table 2).

\section{Discussion}

Subcutaneous panniculitis-like T-cell lymphoma is a rare subtype of cutaneous T-cell lymphoma characterized by an atypical lymphocytic infiltrate, composed of CD3 + /CD4 - /CD8 + cytotoxic T cells in subcutaneous tissue mimicking panniculitis. Although this entity previously included cases composed of $\alpha \beta$ or $\gamma \delta$ T lymphocytes, the 2008 WHO Classification limits the diagnosis of subcutaneous panniculitis-like T-cell lymphoma to those cases in which the neoplastic T cells have an $\alpha \beta$ phenotype. Lymphomas comprised of $\gamma \delta \mathrm{T}$ cells are classified as primary cutaneous $\gamma \delta$ T-cell lymphoma. In contrast to the $\alpha \beta$ cases, $\gamma \delta$ T-cell lymphoma are associated with a more aggressive clinical course and increased risk of developing hemophagocytic syndrome. ${ }^{1,5,6}$

Although subcutaneous involvement of subcutaneous panniculitis-like T-cell lymphoma is often multifocal, the spread of disease to organs other than the skin and subcutaneous tissue is rare. Hypermetabolic infiltrative lesions suspicious for lymphomatous involvement of lung, omental soft tissue and lymph node have been reported in patients diagnosed with subcutaneous panniculitis-like T-cell lymphoma using PET-CT. ${ }^{7-9}$ However, most of these reports lack histological confirmation. In addition, PET-CT lacks specificity in distinguishing lymphoma from other metabolically active nonneoplastic process. One case, reported by Huang et $a l^{7}$ with hypermetabolic signaling in the bone marrow was shown to be associated with hemophagocytic syndrome.

To our knowledge, there is no histological description of bone marrow involvement by subcutaneous panniculitis-like T-cell lymphoma. Willemze et al in a large series of 63 cases of subcutaneous panniculitis-like T-cell lymphoma $\alpha \beta$ type, found hemophagocytosis in the bone marrow of 11 cases but no evidence of lymphoma. ${ }^{6}$ Ghobrial et al examined 21 cases of subcutaneous panniculitislike T-cell lymphoma over a period of 30 years at the 


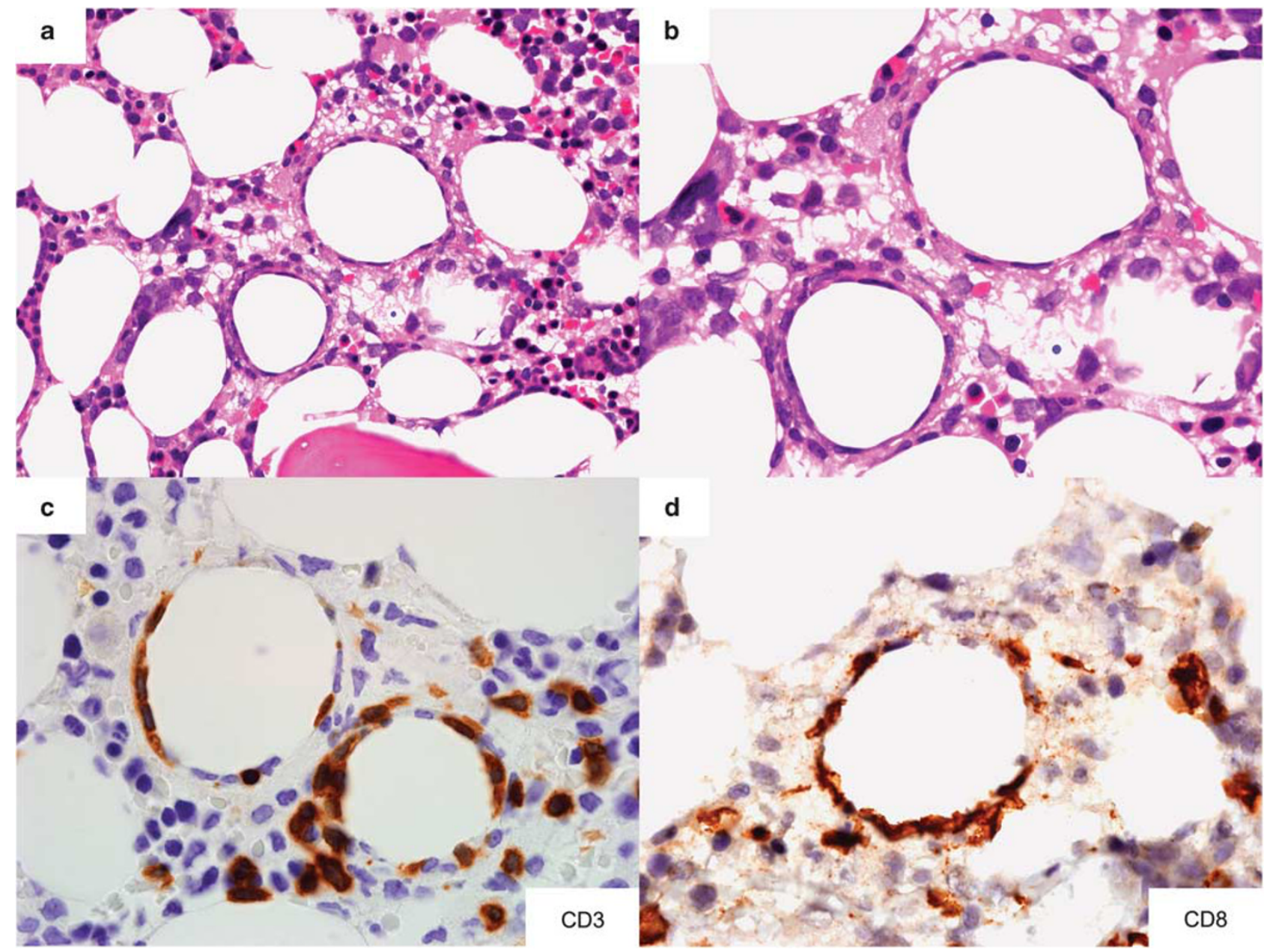

Figure 2 Case 2: (a and b) Bone marrow contained foci of lymphocytes encircling fat cells (hematoxylin and eosin stain, original magnification $(\mathbf{a}) \times 200$, (b) $\times 600)$. (c and d) The lymphocytes were CD3 + and CD8 $+(\mathbf{c}$ and d, immunoperoxidase, original magnification $\times 600$ ).

Mayo Clinic, and found lymphoma in only 1 of 20 bone marrow biopsies. However, it was unclear whether this positive case was of the $\alpha \beta$ phenotype as their series included both $\alpha \beta$ and $\gamma \delta$ type cases, and the case described was published prior to the 2008 WHO classification. ${ }^{10}$

In this study, we reported three cases of subcutaneous panniculitis-like T-cell lymphoma with focal bone marrow infiltration by lymphoma. None of the three bone marrow core biopsies exhibited large lymphocytic infiltrates. However, detailed histologic examinations revealed scattered and subtle multifocal involvement by lymphoma with morphologic features similar to those in the previous subcutaneous tissue biopsies. These changes included rimming of adipocytes by atypical lymphocytes with or without histiocytes. The atypical lymphocytes had hyperchromatic and elongated nuclei. Scattered small interstitial aggregates of lymphocytes and increased number of histiocytes, some containing phagocytized cellular debri, were also present in two cases. The adipocytes surrounded by atypical lymphocytes exhibited blurred cytoplasmic outlines thus lacking the crisp demarcation of normal fat cells. This feature should be considered a clue leading to additional immunohistochemical studies, particularly in patients with a prior history of subcutaneous panniculitis-like T-cell lymphoma. Similar to the subcutaneous lesions, immunohistochemistry is an integral and essential part of the diagnostic workup. In these cases, immunohistochemistry confirmed that the cells rimming adipocytes were cytotoxic T cells with a phenotype identical to the neoplastic cells in the subcutaneous tissue biopsies.

Staging of lymphoma is important in determining the appropriate and effective treatment. In contrast to primary cutaneous $\gamma \delta$ T-cell lymphoma, bone marrow biopsy is not a routine staging procedure for subcutaneous panniculitis-like T-cell lymphoma and other cutaneous lymphomas with indolent clinical behavior as categorized in the WHO-EORTC classification. $^{5}$ In cases of subcutaneous panniculitis-like T-cell lymphoma, bone marrow biopsy is only performed in patients with an elevated LDH, pancytopenia or when there is a 


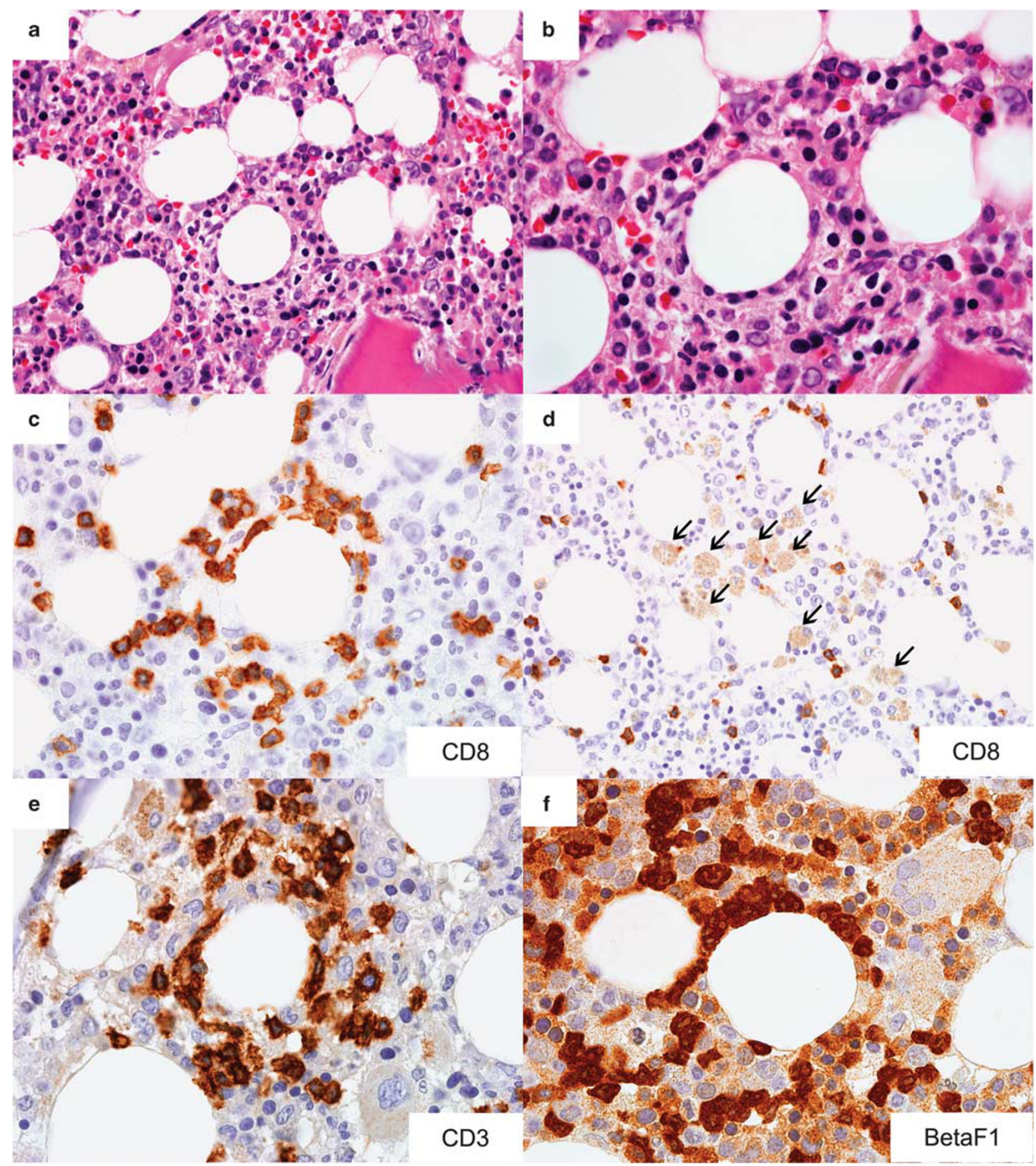

Figure 3 Case 1: (a and b). The bone marrow showed focal lymphohistiocytic infiltrates which rimmed the fat cells (hematoxylin and eosin stain, original magnification $(\mathbf{a}) \times 200$, (b) $\times 600$ ). (c) The adipocytes were surrounded by a significant number of CD8 $+\mathrm{T}$ cells (original magnification $\times 600$ ). (d) Focally increased number of interstitial histiocytes (arrows) and CD8 $+\mathrm{T}$ cells were seen (immunoperoxidase for CD8, original magnification $\times 600)$. (e and f) The lymphocytes were CD3 + and BetaF1 $+(\mathbf{e}$ and $\mathbf{f}$, immunoperoxidase, original magnification $\times 600$ ).

clinical concern for hemophagocytic syndrome; however, there are no clear criteria to select patients who would benefit from a bone marrow biopsy. The currently used TNM classification for primary cutaneous lymphoma categorizes the type and extent of cutaneous lesions (T), nodal involvement $(\mathrm{N})$ and the presence of extracutaneous non-lymph node disease (M). ${ }^{3}$ It is implied 
Table 2 Immunophenotypic and molecular features

\begin{tabular}{|c|c|c|c|}
\hline & Case 1 & Case 2 & Case 3 \\
\hline \multicolumn{4}{|l|}{ Skin and soft tissue lesions } \\
\hline Immunohistochemistry & $\begin{array}{l}\mathrm{CD} 3+, \mathrm{CD} 8+, \mathrm{BetaF} 1+, \mathrm{CD} 4-\text {, } \\
\text { and CD56 - }\end{array}$ & $\begin{array}{l}\text { CD3 +, CD8 +, BetaF1 +, CD45 - , CD56 - , } \\
\text { CD5 - , and EBER - }\end{array}$ & CD3 + and CD8 + \\
\hline $\begin{array}{l}\text { T-cell receptor gene } \\
\text { rearrangement }\end{array}$ & Clonal & Not done & Not done \\
\hline Flow cytometry & Unremarkable & $\begin{array}{l}\text { Abnormal } \\
\text { CD3 +, CD } 4-, \text { CD } 8+, \alpha \beta+, \gamma \delta-\text {, } \\
\text { dim CD56 }+, \text { CD } 16-, \text { CD57 }-, \text { TIA } 1+\text {, and } \\
\text { granzyme B - }\end{array}$ & Not done \\
\hline \multicolumn{4}{|l|}{ Bone marrow } \\
\hline Immunohistochemistry & $\mathrm{CD} 3+, \mathrm{CD} 8+$, BetaF $1+$, and $\gamma \delta-$ & CD3 +, CD4 - , CD8 +, and CD56 + & $\begin{array}{l}\mathrm{CD} 3+, \mathrm{CD} 8+ \\
\text { BetaF1 }+ \text {, and } \gamma \delta-\end{array}$ \\
\hline $\begin{array}{l}\text { T-cell receptor gene } \\
\text { rearrangement }\end{array}$ & Negative & Negative & Not done \\
\hline Flow cytometry & Unremarkable & Unremarkable & Unremarkable \\
\hline
\end{tabular}

that patients are at stage Mo if there is no lymph node or visceral disease. In the cases described here, extensive staging workups using CT and PET-CT, performed in cases 1 and 2, did not show lymphadenopathy, splenomegaly, or evidence of other organ involvement. However, the presence of bone marrow involvement indicated that the disease was not localized to the subcutaneous tissue. On the basis of the TNM classification, the stage would be upgraded to M1. Whether this indicates more widespread disease requiring more aggressive chemotherapy and autologous or allogeneic stem cell transplantation similar to other M1 stage cutaneous lymphomas is not known.

Subcutaneous panniculitis-like T-cell lymphoma has an overall good prognosis with a 5-year median survival of $80 \%$, but about $15-20 \%$ of the patients have an aggressive course. ${ }^{1,6}$ In Willemze et al's large series of 63 cases of subcutaneous panniculitis-like T-cell lymphoma with confirmed $\alpha \beta$ phenotype, 39 patients achieved complete remission after initial treatment, 15 patients had ongoing skin disease, and 9 patients died, including 7 with hemophagocytic syndrome. Hemophagocytic syndrome is considered a strong adverse prognostic indicator. The 5-year survival for patients with subcutaneous panniculitislike T-cell lymphoma and hemophagocytic syndrome is significantly lower than those without hemophagocytic syndrome (46 vs 91\%). ${ }^{6}$ But the prognostic significance of other clinical features or laboratory abnormalities is not conclusive. Two of our three patients (cases 2 and 3) appear to have a more aggressive disease course. Patient 3 did not respond to therapy and died $\sim 9$ months after the initial diagnosis, whereas patient 2 had multiple recurrences and eventually required an allogeneic stem cell transplant. Both patients had clinical concern for hemophagocytic syndrome, but this was not confirmed. The possible independent prognostic value of bone marrow involvement needs further evaluation.

To our knowledge, this is the first series of subcutaneous panniculitis-like T-cell lymphoma with bone marrow involvement. Owing to the small number of cases we encountered, it is difficult to estimate the frequency for bone marrow involvement. Three of the four cases diagnosed in our institution between 1994 and 2013 had bone marrow biopsies available for us to review, and all three which comprise the cases of this study demonstrated bone marrow involvement. Our experience indicates that, although subcutaneous panniculitislike T-cell lymphoma often is confined to the subcutis, subtle and focal involvement of the bone marrow by lymphoma occurs and can be identified histologically and confirmed using standard immunohistochemistry. Flow cytometry and molecular evaluation for T-cell receptor gene rearrangement may be negative, most likely due to focal involvement and the limited number of neoplastic cells. Owing to the small number of cases studied, it is unclear whether these patients need more aggressive clinical intervention. Our observation raises awareness of bone marrow involvement in this rare entity. However, the incidence and significance of bone marrow involvement in subcutaneous panniculitislike T-cell lymphoma requires further evaluation in a larger study.

\section{Disclosure/conflict of interest}

The authors declare no conflict of interest.

\section{References}

1 Jaffe ES, Gualard P, Ralfkiaer E, et al. Subcutaneous panniculitis-like T-cell lymphoma. In: Swerdlow S, Campo E, Harris NL, Jaffe E, Pileri S, Stein S, Thiele J, Vardiman J (eds). WHO Classification of Tumours of Haematopoietic and Lymphoid Tissues, 4th edn. International Agency for Research on Cancer (IARC): Lyon, 2008.

2 Monaghan SA, Peterson LC, James C, et al. Pan B-cell markers are not redundant in analysis of chronic 
lymphocytic leukemia (CLL). Cytometry B Clin Cytom 2003;56:30-42.

3 Kim YH, Willemze R, Pimpinelli N, et al. TNM classification system for primary cutaneous lymphomas other than mycosis fungoides and Sezary syndrome: a proposal of the International Society for Cutaneous Lymphomas (ISCL) and the Cutaneous Lymphoma Task Force of the European Organization of Research and Treatment of Cancer (EORTC). Blood 2007;110:479-484.

4 Henter JI, Horne A, Arico M, et al. HLH-2004: Diagnostic and therapeutic guidelines for hemophagocytic lymphohistiocytosis. Pediatr Blood Cancer 2007;48:124-131.

5 Willemze R, Jaffe ES, Burg G, et al. WHO-EORTC classification for cutaneous lymphomas. Blood 2005;105:3768-3785.

6 Willemze R, Jansen PM, Cerroni L, et al. Subcutaneous panniculitis-like T-cell lymphoma: definition, classifi- cation, and prognostic factors: an EORTC Cutaneous Lymphoma Group Study of 83 cases. Blood 2008;111: 838-845.

7 Huang CT, Yang WC, Lin SF. Positron-emission tomography findings indicating the involvement of the whole body skin in subcutaneous panniculitislike $\mathrm{T}$ cell lymphoma. Ann Hematol 2011;90: 853-854.

8 Kim JW, Chae EJ, Park YS, et al. Radiological and clinical features of subcutaneous panniculitis-like T-cell lymphoma. J Comput Assist Tomogr 2011;35: 394-401.

9 Feeney J, Horwitz S, Gonen M, et al. Characterization of T-cell lymphomas by FDG PET/CT. AJR Am J Roentgenol 2010;195:333-340.

10 Ghobrial IM, Weenig RH, Pittlekow MR, et al. Clinical outcome of patients with subcutaneous panniculitis-like T-cell lymphoma. Leuk Lymphoma 2005;46: 703-708. 